Dr Dragoljub M. Brkice,

dipl. inž.

Tehnicki opitni centar KoV

Beograd
ODREDIVANJE PARAMETARA TROPARAMETARSKE VEJBULOVE RASPODELE PRIMENOM GRAFIČKO-RAČUNSKE METODE

UDC: $519.233: 519.688$

Rezime:

U radu je opisana grafičko-računska metoda za određivanje parametara troparametarske Vejbulove raspodele. Parametar položaja a određuje se tako što mu se zadaju razne vrednosti $i$ prati oblik Henrijeve krive na Vejbulovom verovatnosnom papiru. Zadata vrednost za parametar a, pri kojoj Henrijeva kriva prelazi u Henrijevu pravu, predstavlja tačkastu ocenu parametra položaja a. Nakon određivanja parametra položaja a, vrši se transformacija troparametarske $u$ dvoparametarsku Vejbulovu raspodelu čiji se parametar razmere $b$ i parametar oblika c određuju pomoću poznate metode Henrijeve prave na Vejbulovom verovatnosnom papiru. Radi ilustracije praktične primene ove metode, dat je primer određivanja parametara $a, b$ i c primenom elektronskog računara $i$ priloženog računarskog programa.

Ključne reči: Vejbulova raspodela, grafičko-računska metoda, određivanje parametara raspodele.

\title{
DETERMINATION OF PARAMETERS OF THE THREE-PARAMETER WEIBULL DISTRIBUTION BY A GRAPHIC-CALCULATION METHOD
}

\section{Summary:}

A graphic-calculation method for determining parameters of the three-parameter Weibull distribution is described. The a position parameter is determined by following the form of the Henry's curve on the Weibull probability paper. The given value of the parameter a for which the Henry's curve passes into the Henry's straight line, repressents the point evaluation of the a position parameter. After the determination of the a position parameter the three - parameter Weibull distribution is transformed into the two-parameter one of which the $b$ proportion parameter and the $c$ form parameter are determined by the method of the Henry's straight line on the Weibull probability paper. In order to illustrate the application of this method, the article gives on example of determining the parameters $a, b$ and $c$ by a computer and the given calculating program.

Key words: Weibull distribution, graphic-calculation method, detemination of distribution parameters.

\section{Uvod}

Vejbulova raspodela jedna je od najčešće korišćenih raspodela $u$ inženjerskoj praksi pri analizama efikasnosti tehničkih sistema, a posebno u području pouzdanosti, u vezi sa vekom proizvoda, što proističe iz njenog parametarskog karaktera i širokih mogućnosti da se izborom odgovarajućih vrednosti ovih parametara interpretiraju veoma različiti zakoni slučajno promenljivih veličina. 
Po ovoj metodi, najpre se odredi vrednost parametra položaja a Vejbulove raspodele, korišćenjem Henrijevih krivih dobijenih na Vejbulovom verovatnosnom papiru. $\mathrm{Na}$ samom početku izračunavanja, parametru a dodeli se neka pozitivna vrednost. Ako se parametru a dodeli vrednost koja je manja od njegove stvarne vrednosti, onda se dobija kriva koja je konkavna $u$ odnosu na $\mathrm{x}$-osu. U ovom slučaju, ako se povećava pretpostavljena vrednost za veličinu a, Henrijeva kriva se ispravlja i u momentu kada se parametru a dodeli vrednost koja je jednaka njegovoj stvarnoj vrednosti, Henrijeva kriva prelazi u Henrijevu pravu. Pretpostavljena vrednost parametra a, pri kojoj Henrijeva kriva prelazi $u$ pravu, predstavlja tačkastu ocenu ovog parametra. Ako je pretpostavljena vrednost za parametar a veća od njegove stvarne vrednosti, tada Henrijeva kriva postaje konveksna $u$ odnosu na x-osu.

Smanjivanjem pretpostavljene vrednosti za parametar a smanjuje se konveksnost Henrijeve krive i u momentu kada se parametru a dodeli vrednost koja je jednaka njegovoj stvarnoj vrednosti, Henrijeva kriva prelazi u pravu. Dakle, istražuje se vrednost parametra a pri kojoj Henrijeva kriva menja svoju konkavnost u konveksnost, ili obratno, i ta vrednost se označava kao tačkasta ocena parametra položaja a. Kada se odredi vrednost parametra a, onda se od svake dobijene vrednosti slučajne promenljive $t_{i}(i=1,2, \ldots, n)$ oduzme tačkasta ocena $\hat{a}, t j . t_{i}-\hat{a} \mathbf{i}$ tako izvrši transformacija troparametarske $u$ dvoparametarsku Vejbulovu raspodelu. Posle toga, parametar razmere b i parametar oblika c određuju se poznatom metodom Henrijeve prave na Vejbulovom verovatnosnom papiru ili nekom drugom poznatom metodom.

\section{Teorijska osnova}

Funkcija troparametarske Vejbulove raspodele ima oblik:

$F(t)=1-e^{-\left(\frac{t-a}{b}\right)^{c}} ; a \geqslant 0, b, c>0, t \geqslant a$.

gde je:

$\mathrm{t}$ - slučajno promenljiva veličina;

a - parametar položaja;

b - parametar razmere;

c - parametar oblika.

Kada slučajno promenljiva $t$ ima vrednosti $t_{i} ; i=1,2, \ldots, n$, koje se urede $u$ rastućem poretku: $t_{1} \leqslant t_{2} \leqslant$ $\leqslant \ldots \leqslant t_{n}$, gde je $n$ ukupan broj vrednosti (veličina uzorka), tada funkcija raspodele poprima vrednosti: $F(t)=$ $=F\left(t_{i}\right)=F_{i}$. Dakle, za i-tu vrednost slučajne promenljive $t$, izraz (1) glasi:

$$
F_{i}=F\left(t_{i}\right)=1-e^{-\left(\frac{t_{i}-a}{b}\right)^{c}}
$$

Izraz (2) može se napisati i u sledećem obliku:

$$
\begin{gathered}
\frac{1}{1-F_{i}}=e^{\left(\frac{t_{i}-a}{b}\right)^{c}} \\
\ln \left[\ln \left(\frac{1}{1-F_{i}}\right)\right]=\ln \left(\frac{t_{i}-a}{b}\right) \\
\ln \left[\ln \left(\frac{1}{1-F_{i}}\right)\right]=\ln \left(t_{i}-a\right)-c \ln b .
\end{gathered}
$$

Uvodeći smene:

$$
\begin{gathered}
c=A \\
-\ln b=B \\
x_{i}=\ln \left(t_{i}-a\right) \\
y_{i}=\ln \left[\ln \left(\frac{1}{1-F_{i}}\right)\right] ; \quad F_{i}=\frac{i}{n+1},
\end{gathered}
$$

izraz (3) dobija oblik:

$$
\mathrm{y}_{\mathrm{i}}=\mathrm{Ax}_{\mathrm{i}}+\mathrm{B}
$$


Koeficijenti A i B u izrazu (8), određuju se pomoću sledećih izraza [1]:

$$
\begin{aligned}
& A=\frac{\sum_{i=1}^{n} x_{i} \sum_{i=1}^{n} y_{i}-n \sum_{i=1}^{n} x_{i} y_{i}}{\left(\sum_{i=1}^{n} x_{i}\right)^{2}-n \sum_{i=1} x_{i}^{2}} \\
& B=\frac{\sum_{i=1}^{n} x_{i} \sum_{i=1}^{n} x_{i} y_{i}-\sum_{i=1}^{n} x_{i}^{2} \sum_{i=1}^{n} y_{i}}{\left(\sum_{i=1}^{n} x_{i}\right)^{2}-n \sum_{i=1}^{n} x_{i}^{2}}
\end{aligned}
$$

Iako po izgledu izraz (8) predstavlja jednačinu prave, to nije prava ako parametar položaja a nije jednak nuli. Dakle, ako je $a \neq 0$, tada se skup tačaka $\left(x_{i}, y_{i}\right)$, koje su određene izrazima (6) i (7), u ravni ( $x, y)$ na Vejbulovom verovatnosnom papiru gomila oko zamišljene krive.

\section{Određivanje parametra položaja}

Neka slučajno promenljiva $\mathbf{t} \mathbf{u}$ toku eksperimenta ima vrednosti $t_{1}, t_{2}$, $\ldots, t_{n}$ koje su uređene $u$ rastućem poretku, $t j . t_{1} \leqslant t_{2} \leqslant \ldots \leqslant t_{n}$. Ako se pomoću izraza (6) i (7) izvrše transformacije $t_{i} u x_{i}$ i $F_{i} u y_{i} i$ usvoji da je parametar $\mathrm{a}=0$, a te tačke sa koordinatama $x_{i}$ i $y_{i}$ nanesu na Vejbulov verovatnosni papir, tada će se taj skup tačaka gomilati oko tzv. Henrijeve krive (slika 1). U slučaju kada se skup ovih tačaka gomila oko tzv. Henrijeve prave, pretpostavljena vrednost parametra položaja $a=0$ je istinita a time $\mathrm{i}$ određena. Drugim rečima, radi se o dvoparametarskoj raspodeli koja je specijalan slučaj troparametarske Vejbulove raspodele kod koje je parametar položaja $a=0$. Razmotrimo sada slučaj kada je vrednost parametra položaja $a>0$ tj. kada se skup dobijenih tačaka $\left(\mathrm{x}_{\mathrm{i}}, \mathrm{y}_{\mathrm{i}}\right)$ gomila oko zamišljene krive. Ako pretpostavka da je $a=0$ nije tačna, vrednosti $t_{i}$, koje ima slučajno promenljiva $t$, sadrže $u$ sebi $i$ vrednost parametra a. Kada se od vrednosti $t_{i}$ oduzme pretpostavljena mala vrednost za a koja je znatno manja od stvarne vrednosti a, tada zamišljena kriva $\mathrm{C}$ na slici 1 postaje konkavna $\mathrm{u}$ odnosu na x-osu. Ako se kroz ekstremne tačke $x_{1}$ i $x_{n}$ povuče prava, onda će se uočiti rastojanje između presečne tačke $x_{p}$ ove prave i presečne tačke $x_{c}$ krive C. Ako se povećava vrednost parametra a, kriva $C$ se postepeno ispravlja i $x_{p} \rightarrow x_{c}$. Umesto teorijske krive $C$, koja bi se uklapala (fitovala) u skup tačaka u ravni $(x, y)$, ovde je ta kriva aproksimovana "cik-cak" krivom linijom dobijenom spajanjem $u$ niz tačaka tog skupa.

U momentu kada je data vrednost parametru a izuzetno bliska njegovoj stvarnoj vrednosti, tačke $x_{p} i x_{c}$ se poklapaju, a kriva $C$ prelazi u pravu. Vrednost koja je tada bila data parametru a predstavlja tačkastu ocenu ovog parametra:

$$
\hat{\mathrm{a}}=\mathrm{a}_{\mathrm{dato}}\left(\mathrm{x}_{\mathrm{p}}=\mathrm{x}_{\mathrm{c}}\right) \text {. }
$$

Ako bi se posle ovoga nastavilo sa povećanjem datih vrednosti parametru a, tada bi kriva $C$ postajala sve konveksnija u odnosu na $\mathrm{x}$-osu, a tačka $\mathrm{x}_{\mathrm{p}}$ bila bi sa leve strane tačke $x_{c}$. Dakle, kada je pretpostavljena vrednost za parametar a manja od njegove stvarne vrednosti, tada je kriva C konkavna u odnosu na $\mathrm{x}$-osu, a kada je pretpostavljena vrednost parametra a veća od njegove stvarne vrednosti, kriva $\mathrm{C}$ je konveksna u odnosu na x-osu. Parametru položaja a ne mogu se davati vrednosti koje su jednake ili veće od najmanje vrednosti koje ima slučajno promenljiva $t, t j$. uvek mora biti ispunjen uslov:

$$
\mathrm{a}_{\text {dato }}<\mathrm{t}_{\min }=\mathrm{t}_{\mathrm{l}} .
$$




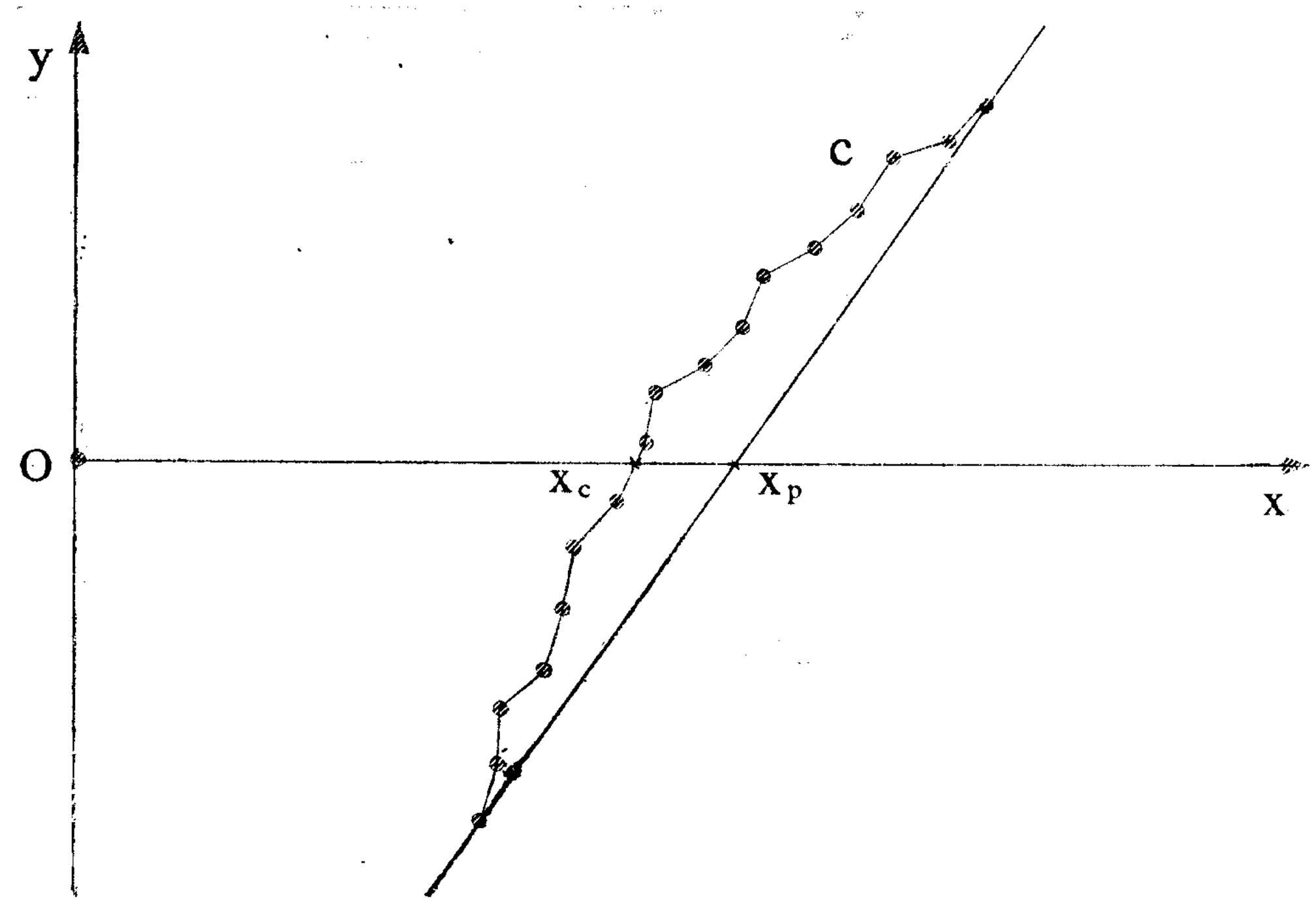

Sl. 1 - Henrijeva kriva

\section{Određivanje parametara} razmere i oblika

U momentu kada kriva C menja svoju konkavnost u konveksnost, odnosno kada prelazi u pravu, tada se, pored trenutno date vrednosti parametru a, koja predstavlja njegovu tačkastu ocenu â, zapamte (zabeleže) i sve vrednosti za $x_{i}$ i $y_{i}(i=1,2, \ldots, n)$. Unošenjem ovih vrednosti $u$ izraze (9) i (10), dobijaju se vrednosti koeficijenata A i B. Na osnovu veze između ovih koeficijenata i parametara b i c, prema izrazima (4) i (5), dobija se:

$$
\begin{aligned}
& \hat{\mathrm{c}}=\mathrm{A} \\
& \hat{\mathrm{b}}=\exp \left(-\frac{B}{\mathrm{~A}}\right) .
\end{aligned}
$$

Pomoću izraza (13) i (14) određuju se tačkaste ocene parametra ob- lika c i parametra razmere b, respektivno.

\section{Određivanje parametara Vejbulove raspodele primenom računara}

Zbog velikog broja ponavljanja izračunavanja potrebnih veličina, za ovu metodu je neophodna primena računara. Radi toga je razvijen računarski program (prilog A). Međ̋utim, zbog njegove obimnosti izostavljen je potprogram pomoću kojeg se dimenzioniše i crta pravougli koordinatni sistem $(\mathrm{x}, \mathrm{y})$ gde se prikazuju Henrijeve krive i Henrijeva prava i potprogram pomoću kojeg se unose vrednosti slučajno promenljive t. Ovaj potprogram omogućava i ručno i automatsko unošenje podataka za slučajno promenljivu t. Pod automatskim unošenjem podataka podrazumeva se generisanje pseudoslučajnih brojeva koji imaju 
troparametarsku Vejbulovu raspodelu sa unapred datim vrednostima parametara a, b i c. Priloženi računarski program urađen je $\mathrm{u}$ turbo basicu, a može se uraditi i sopstveni program koristeći neki drugi programski jezik i pomoću njega proveriti valjanost $i$ efikasnost.

Prilog $A$

Računarski program

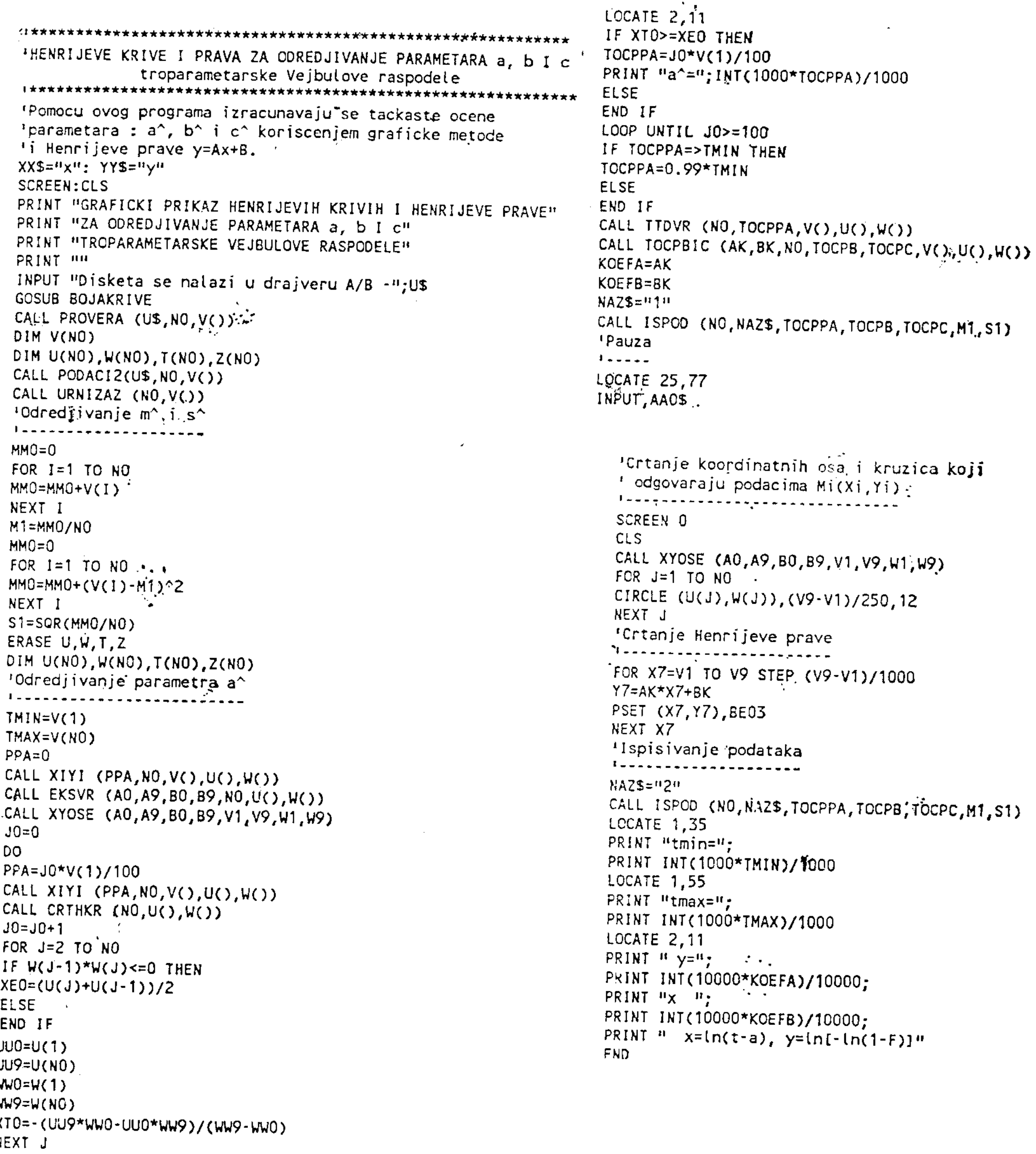


'Transformisanje troparametarske u

'dvoparametarsku vejbulovu raspodelu

SUB TTDVR (NO, TOCPPA, V(1),U(1),W(1))

FOR $J=1$ TO NO

$V(J)=V(J)-T O C P P A$

NEXT J

FOR $J=1$ TO NO

$U(J)=\operatorname{LOG}(V(J))$

$H(J)=\operatorname{LOG}(\operatorname{LOG}((N O+1) /(N O+1-J)))$

NEXT $J$

ENO SUB

Iodredjivanje tackastih ocena $b^{\wedge} j c^{\wedge}$

1....

SUB TOCPBIC (AK, BK, NO, TOCPB, TOCPC, V(1), U(1),W(1))

$S X=0$.

$S Y=0^{\circ}$

$5 \times 2=0$

$S X Y=0$

FOR $J=1$ TO $N O^{*}$

$S X=S X+U(J)$

$S Y=S Y+W(J)$

$S \times 2=S \times 2+U(J) \wedge 2$

$S X Y=S X Y+U(J) * W(J)$

NEXT $\cdot J$

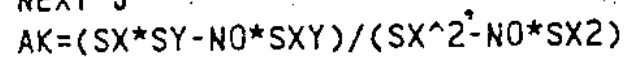

$B K=\left(S X * S X Y-S X Z^{\star} S Y\right) /\left(S X^{\wedge} 2-N O * S X Z\right)$

$T O C P B=E X P(-B K / A K)$

$T O C P C=A K$

END SUB

lodredjivanje vrednosti $\mathrm{za} X \mathrm{X}$ i $Y_{\mathrm{I}}$

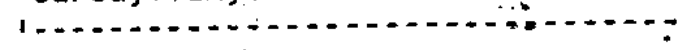

SUB XIYI (PPA,NO,V(1),U(1),W(1)):

$: X j=\ln (t i-a)$

' $Y i=\ln (\ln (1 /(1-F i)))$ je kvantil kojem

lodgovara vrednost funkcije raspodele $F i=i /(n+1)$.

iVrednosti $X i$ poredjane su u rastucem poretku.

SS $=0$

00

$S S=S S+1$

$X 6=V(S S)$

$Y 6=S S /(N O+1)$

$U(S S)=L O G(X 6: P P A)$

$F O=\operatorname{LOG}(\operatorname{LOG}(1 /(1-Y 6)))$

$W(S S)=F O$

LOOP UNTIL SS $>=N O$

END SUB

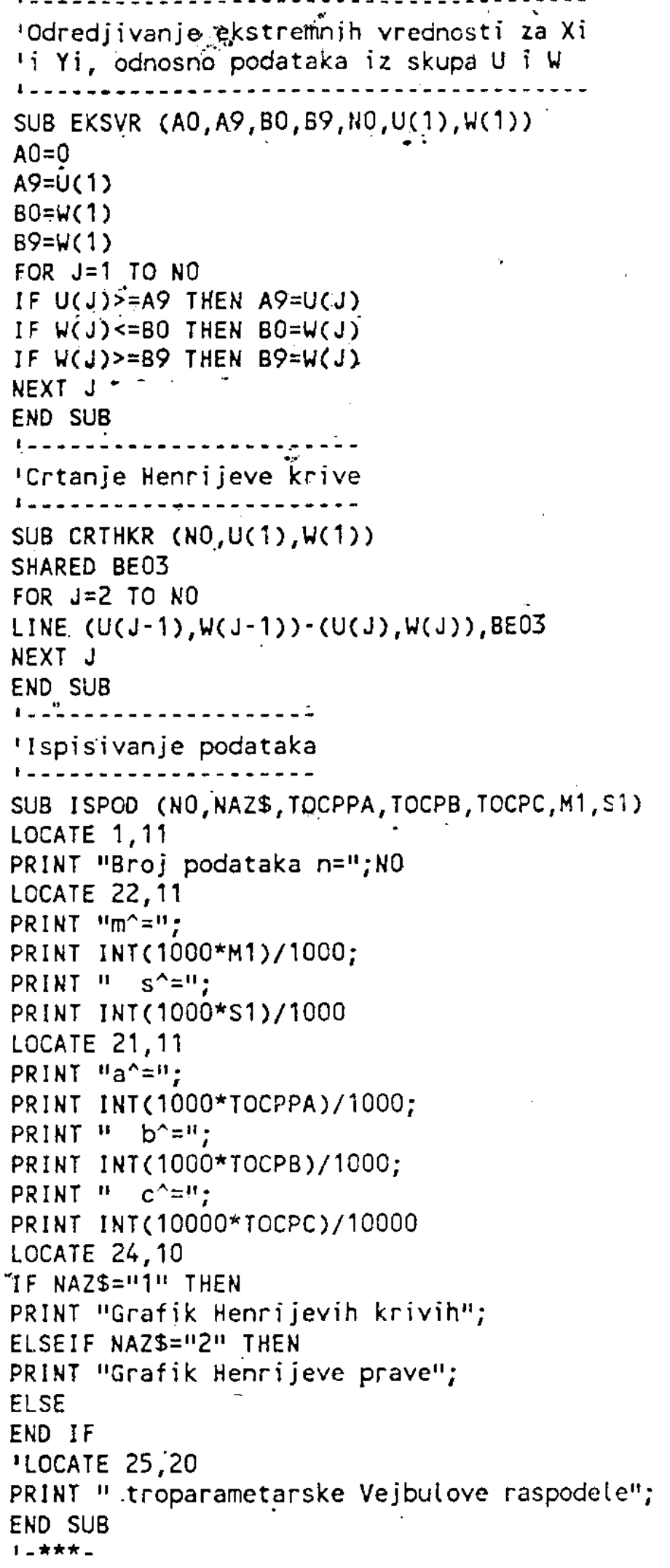

'Odredjivanje ekstreminih vrednosti za Xi

' $Y i$, odnosno podataka iz skupa $U$ i $W$

SUB EKSVR (AO,A9,BO, 69,NO,U(1),H(1))

$A O=0$

'Crtanje Henrijeve krive

SUB CRTHKR (NO,U(1),W(1))

SHARED BEO3

FOR $J=2$ TO NO

LINE. $(U(J-1), W(J-1))-(U(J), W(J)), 8 E 03$

NEXT J

END SUB

IIspisivanje podataka

SUB ISPOD (NO, NAZ\$, TOCPPA, TOCPB, TOCPC, M1, S1)

LOCATE 1,19

PRINT "Broj podataka $n="$;NO

LOCATE 22, 11

PRINT " $s^{\wedge}="$ "

PRINT INT $\left(1000^{*} \mathrm{~S} 1\right) / 1000$

LOCATE 21,11

PRINT INT(1000*TOCPPA)/1000;

PRINT " $b \wedge=1 "$

PRINT INT(1000*TOCPB)/1000

PRINT " $c^{\wedge}=! 1$.

LOCATE 24,10

IF NAZ\$ $=" 1 "$ THEN

PRINT "Grafix Henr

ELSE

END IF

END SUB

Pomoću računarskog programa, $u$ kojem su korišćene izvedene relacije, dobijen je grafik Henrijevih krivih koji je prikazan na slici 2 . Na ovoj slici ispisane su $\mathrm{i}$ vrednosti tačkastih ocena parametara a, b i c, kao i srednje vrednosti $\mathrm{m}$, standardne devijacije $\sigma \mathrm{i}$ broj podataka n. U gornjem levom delu slike 2, ispod $\gg B r o j$ podataka $n=30 \ll$, napisano je $a=241.031$, što je vrednost koja je data parametru a, a pri kojoj je Henrijeva kriva prešla 
Pseudoslučajni brojevi (u neuređenom poretku) koji imaju troparametarsku Vejbulovu raspodelu sa parametrima: $a=250, b=100 i c=2,5$

\begin{tabular}{|c|c|c|c|c|c|c|c|c|c|}
\hline i & $V(i)$ & $\mathrm{i}$ & $V(i)$ & $\mathrm{i}$ & $V(i)$ & $\mathrm{i}$ & $V(i)$ & i & $V(i)$ \\
\hline 1. & 278,58 & 2. & 444,84 & 3. & 329,34 & 4. & 369,95 & 5. & 419,16 \\
\hline 6. & 399,87 & 7. & 325,51 & 8. & 313,18 & 9. & 354,53 & 10. & 355,17 \\
\hline 11. & 289,86 & 12. & 315,35 & 13. & 391,16 & 14. & 366,56 & 15. & 331,61 \\
\hline 16. & 261,99 & 17. & 307,96 & 18. & 353,04 & 19. & 425,82 & 20. & 294,17 \\
\hline 21. & 328,05 & 22. & 303,22 & 23. & 302,45 & 24. & 323,42 & 25 & 308,32 \\
\hline 26. & 327,46 & 27. & 348,70 & 28. & 366,23 & 29. & 301,98 & 30. & 368,85 \\
\hline
\end{tabular}

Tabela 2

Pseudoslučajni brojevi (u rastućem poretku) koji imaju troparametarsku Vejbulovu raspodelu sa parametrima: $a=250, b=100$ i $c=2,5$

\begin{tabular}{|rrrrrrrr|}
\hline $\mathrm{i}$ & $\mathrm{V}(\mathrm{i})$ & $\mathrm{i}$ & $\mathrm{V}(\mathrm{i})$ & $\mathrm{i}$ & $\mathrm{V}(\mathrm{i})$ & $\mathrm{i}$ & $\mathrm{V}(\mathrm{i})$ \\
\hline 1. & 261,99 & 2. & 278,58 & 3. & 289,86 & 4. & 294,17 \\
5. & 301,98 & 6. & 302,45 & 7. & 303,22 & 8. & 307,96 \\
9. & 308,32 & 10. & 313,18 & 11. & 315,35 & 12. & 323,42 \\
13. & 325,51 & 14. & 327,46 & 15. & 328,05 & 16. & 329,34 \\
17. & 331,61 & 18. & 348,70 & 19. & 353,04 & 20. & 354,53 \\
21. & 355,17 & 22. & 366,23 & 23. & 366,56 & 24. & 368,85 \\
25. & 369,95 & 26. & 391,16 & 27. & 399,87 & 28. & 419,16 \\
29. & 425,82 & 30. & 444,84 & & & & \\
\hline
\end{tabular}

u pravu i ta vrednost je uzeta kao tačkasta ocena parametra a.

Posle toga nastavljeno je sa povećanjem vrednosti za parametar a da bi se videlo kako Henrijeva kriva menja svoju konkavnost $\mathrm{u}$ konveksnost. Pri ovom povećanju vrednosti parametra a vodilo se računa o uslovu iskazanom relacijom (12).

U momentu kada je izvršena ocena parametra položaja a izvršena je i transformacija troparametarske $u$ dvoparametarsku Vejbulovu raspodelu i pri tom dobijena Henrijeva prava (slika 3).

Na slici 3 prikazan je skup tačaka kroz koji je fitovana (uklopljena)
Henrijeva prava. U gornjem delu ove slike prikazan je broj podataka $n$, najmanja i najveća vrednost $t_{\min } i t_{\max }$ pseudoslučajnih brojeva, kao i jednačina Henrijeve prave: $y=2,252 x-$ $-10,647$ u kojoj se vidi da je $A=2,252$ i $B=-10,647$. Na slici su ispisani $i$ transformacioni izrazi: $x=\ln (t-a) \quad i$ $y=\ln [-\ln (1-F)]$ pomoću kojih se transformiše promenljiva $t \mathrm{u} x \mathrm{i}$ promenljiva $\mathrm{F} u \mathrm{y}$.

Tako su, primenom ove metode, uz korišćenje računara određeni parametri troparametarske Vejbulove raspodele $\mathrm{a}, \mathrm{b}$ i $\mathrm{c}$, tj. dobijene njihove tačkaste ocene: $\hat{a}=241,031 ; \hat{b}=113,022$ i $\hat{c}=2,252$ uz grafičke prikaze. 


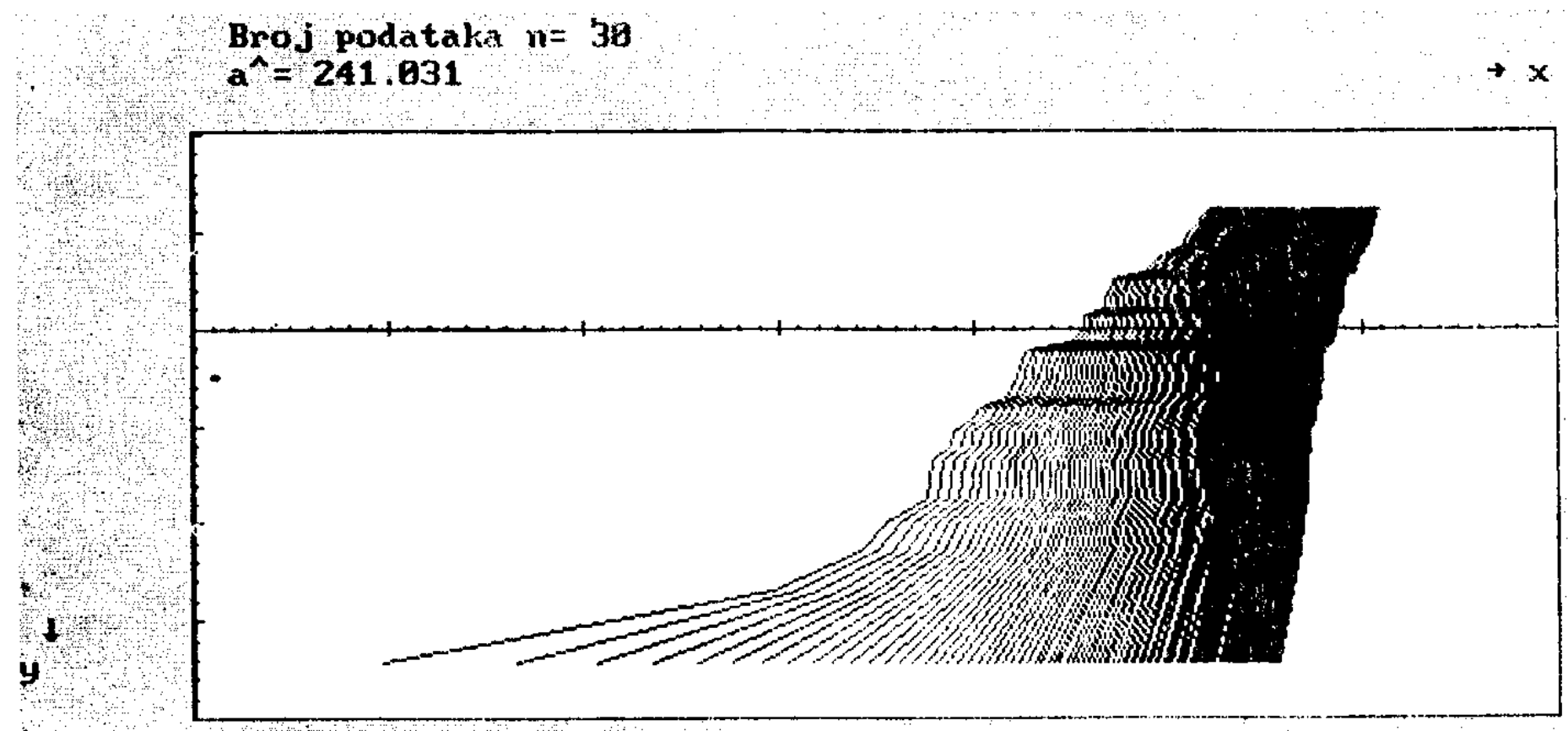

$a^{\wedge}=241.031 \quad b^{\wedge}=113.622 \quad c^{\wedge}=2.252$

$\mathrm{m}^{\wedge}=340.21, \mathrm{~s}^{\wedge}=43.832$

Grafik Henri jeuih krivih troparametarske Vejbulowe raspodele

Sl. 2 - Grafik Henrijevih krivih troparametarske Vejbulove raspodele

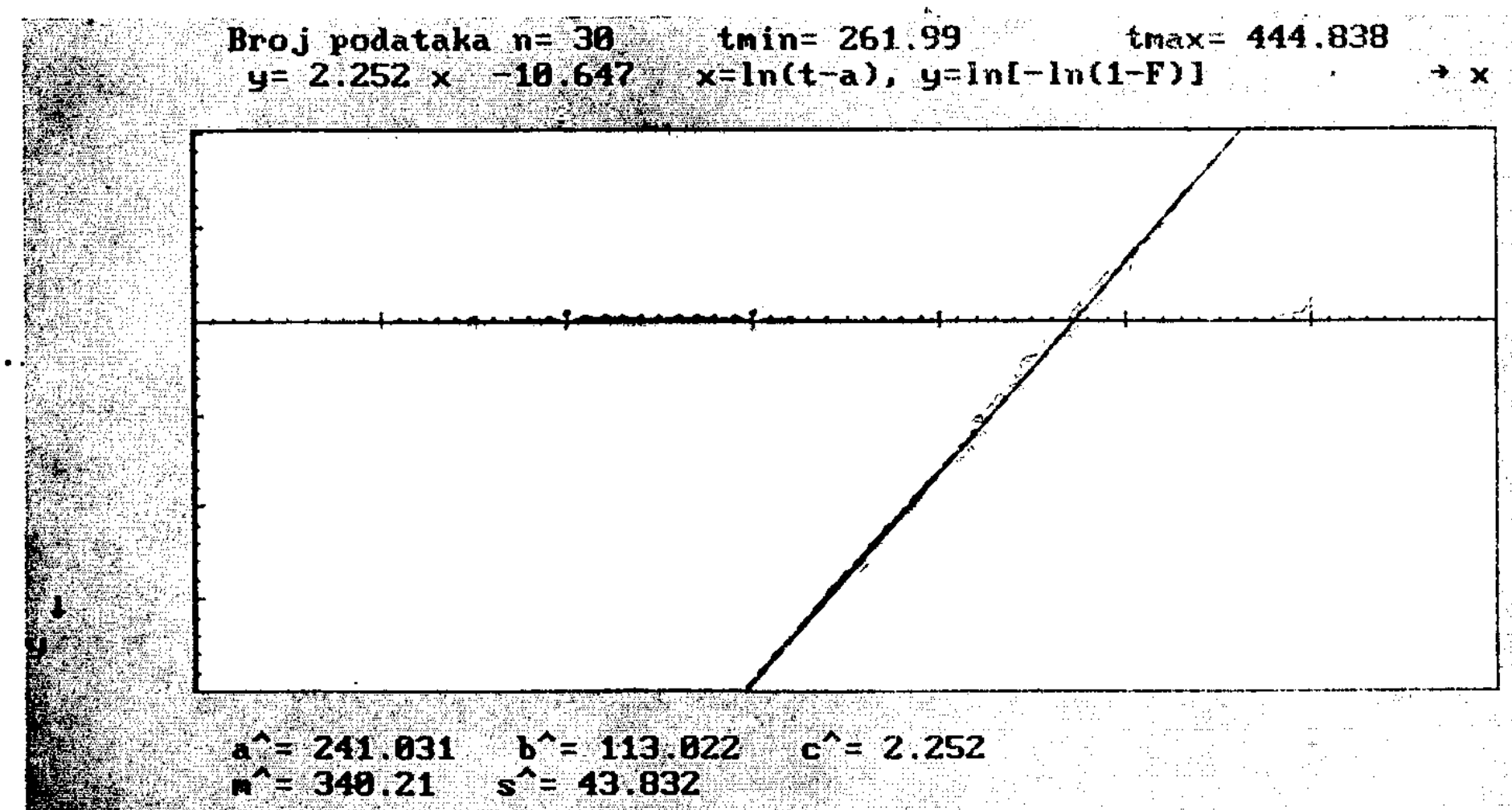

Graf ik Henri jeve prave troparametarske Vejbulove raspodele

Sl. 3 - Grafik Henrijeve prave troparametarske Vejbulove raspodele 


\section{Zaključak}

Kada se uporede dobijene vrednosti tačkastih ocena: $\hat{a}=241,031$, $\hat{b}=113,022$ i $\hat{c}=2,252$ sa usvojenim vrednostima parametara: $a=250, b=100$ i $c=2,5$, pri kojima su generisani pseudoslučajni brojevi, na osnovu kojih su izračunate ove tačkaste ocene, može se zaključiti da je postignuta zadovoljavajuća tačnost u statističkom smislu.

Literatura:

[1] P. Chapouille et R. De Pazzis: Fiabilité Systèmes, Masson, Paris, 1968.
Pomoću datog programa realizovana je provera opisane metode više puta, a dobijeni rezultati u većini slučajeva su zadovoljavajući. Može se očekivati da će navedena metoda određivanja parametara troparametarske Vejbulove raspodele biti efikasna i u slučaju njene primene na vrednosti $t_{1}, t_{2}, \ldots, t_{n}$ koje slučajno promenljiva $t$ poprima $u$ toku nekog eksperimenta.

[2] B. L. Van Der Waerden: Mathematische Statistik, Springer-Verlag, Berlin, 1965. 